\title{
Efficacy of Bacteriophages in Propionibacterium acnes-Induced Inflammation in Mice
}

\author{
Min Ji Kim, Dong Hyuk Eun, Seok Min Kim, Jungmin Kim ${ }^{1}$, Weon Ju Lee \\ Departments of Dermatology and ${ }^{1}$ Microbiology, School of Medicine, Kyungpook National University, Kyungpook National University \\ Hospital, Daegu, Korea
}

Background: Bacteriophages have been introduced as living drugs for infectious diseases; thus, they may provide an alternative to conventional acne therapeutics in patients with non-responsive acne. Objective: We investigated the effect of bacteriophages using an acne mouse model with Propionibacterium acnes-induced inflammatory nodules by clinical examination, pathology, and immunohistochemical analysis. Methods: A human-isolated $P$. acnes suspension $\left(10^{9}\right.$ colony forming units/ $\left.\mu \mathrm{l}\right)$ was injected into the backs of HR-1 mice. Group A was used as a control, Group B was injected on the back with $P$. acnes 4 weeks following the initial $P$. acnes suspension injection, and group $C$ was injected on the back with $P$. acnes and bacteriophages 4 weeks following the initial $P$. acnes suspension injection. Clinical and histopathological evaluations were performed. Results: Inflammatory nodule size decreased with time in all groups. Group C showed the greatest decrease in size, followed by group B and group A. The histopathological findings showed a decrease in epidermal thickness and the number and size of microcomedone-like cysts in groups $\mathrm{B}$ and $\mathrm{C}$ compared to group A. Immunohistochemistry revealed similar expression of integrin $\alpha 6$, the epidermal proliferation marker, infiltration of CD4/CD8 T cells and neutrophils, and expression of

Received April 20, 2018, Revised August 1, 2018, Accepted for publication August 2, 2018

Corresponding author: Weon Ju Lee, Department of Dermatology, Kyungpook National University Hospital, 130 Dongdeok-ro, Jung-gu, Daegu 41944, Korea. Tel: 82-53-420-5838, Fax: 82-53-426-0770, E-mail: weonju@knu.ac.kr

ORCID: https://orcid.org/0000-0001-5708-1305

This is an Open Access article distributed under the terms of the Creative Commons Attribution Non-Commercial License (http://creativecommons. org/licenses/by-nc/4.0) which permits unrestricted non-commercial use, distribution, and reproduction in any medium, provided the original work is properly cited.

Copyright $(c)$ The Korean Dermatological Association and The Korean Society for Investigative Dermatology myeloperoxidase, interleukin- $\beta$, toll-like receptor-2, LL-37, and matrix metalloproteinase-2/3/9 in all three groups. Conclusion: Using an acne mouse model with $P$. acnes-induced inflammatory nodules, we demonstrate that bacteriophages may constitute an alternative to conventional acne therapies. However, additional studies are needed for human applications. (Ann Dermatol 31(1) $22 \sim 28,2019$ )

\section{-Keywords-}

Acne vulgaris, Bacteriophage, Mice, Propionibacterium acnes

\section{INTRODUCTION}

Acne vulgaris is a very common skin disease of the pilosebaceous follicles characterized by comedones, papules, pustules, nodules, and cysts ${ }^{1}$. One of the main causative factors of acne is colonization of the follicular infundibulum and sebaceous duct by Propionibacterium acnes. P. acnes plays an important role in inducing an inflammatory event $^{2}$. In addition, $P$. acnes can lead to the development of abnormal differentiation and keratinization in epidermal keratinocytes ${ }^{1}$. Therefore, $P$. acnes may act as a major causative factor in early inflammatory papules of acne.

The establishment of animal models for various diseases is helpful for expanding research fields and developing the production of new therapeutic modalities. Although there are various acne animal models, such as the Mexican hairless dog, the Rhino mouse, and the rabbit ear assay, elucidative models are still needed ${ }^{3}$. Previously, we reported the establishment of an acne mouse model; HR-1 mice develop acne-like inflammatory nodules on their backs following injection of $P$. acnes, in contrast to BALB/C, VDR 
k/o, and SCID mice ${ }^{4}$.

Bacteriophages are bacterial viruses consisting of proteins that encapsulate a DNA or RNA genome ${ }^{5}$; they are widely distributed in sites populated by bacteria. Bacteriophages replicate within bacteria after injecting their genome into the bacterial cytoplasm. They tend to kill only specific pathogens without damaging the normal flora; thus, they can be used as living drugs for bacterial infections, including acne ${ }^{6}$. Bacteriophages targeting $P$. acnes have been isolated from acne patients ${ }^{7}$.

In this study, we investigated the efficacy of bacteriophages in a $P$. acnes-induced acne mouse model by clinical examination, histopathology, and immunohistochemical studies.

\section{MATERIALS AND METHODS}

\section{$P$. acnes culturing}

P. acnes (ATCC 11828) were isolated from pustular lesions of Korean patients with moderate inflammatory acne. $P$. acnes from post log phase cultures were grown on brain heart infusion agar under anaerobic conditions at $37^{\circ} \mathrm{C}$. $P$. acnes cells were harvested by centrifugation at $5,000 \times \mathrm{g}$ for 10 minutes, washed three times with phosphate buffered saline (PBS), and resuspended to a concentration of $10^{9}$ colony forming units $/ \mathrm{ml}$ in PBS for the experiments.

\section{Acne mouse model using HR-1 mice and injection of $P$. acnes and/or bacteriophages into HR-1 mice}

Six-week-old female Hos:HR-1 mice (HR-1; SLC Inc., Hamamatsu, Japan) were maintained under conventional laboratory conditions following 1 week of acclimation. A live $P$. acnes suspension was injected intradermally $(20 \mu \mathrm{l}$ aliquots), using a 30-gauge needle, on both sides of the backs of three mice per group (group A, group B, and group C). Group A was used as the control; Group B was re-injected with $P$. acnes on the back 4 weeks following the first $P$. acnes injection; and Group $C$ was injected with $P$. acnes and bacteriophages on the back 4 weeks following the first $P$. acnes injection. Bacteriophages were injected intradermally in $20 \mu \mathrm{l}$ aliquots at the $P$. acnes injection site. This procedure was performed in accordance with the institutional guidelines for the care and use of laboratory animals (KNU-2016-0112).

\section{Bacteriophage preparation}

Bacteriophages (KNU, Daegu, Korea) against $P$. acnes were cultured and diluted using tryptone agar plates, tryptone soft agar tubes, and tryptone broth tubes. The bacteriophages were prepared at a concentration of $2.5 \times 10^{6}$ plaque forming units (PFU)/ml. The concentration was determined using the following formula: $\mathrm{PFU} / \mathrm{ml}=$ number of plaques/d $\times v$ (d: dilution, v: volume of diluted virus added to the plate).

\section{Evaluation of clinical changes}

The degree of clinical inflammatory changes was evaluated using digital photography at baseline and at week 1 , 2, 3 and 4 post the first injection in group $A$ and after the second injection in groups $B$ and $C$.

\section{Histological examination}

Mouse tissue samples were collected at week 2 and 4 after the first injection in group $\mathrm{A}$ and after the second injection in groups $B$ and $C$. Eight tissue samples were collected from group $A$, six from group $B$, and six from group C. Paraffin-embedded tissue sections (3- $\mu \mathrm{m}$ thick) were processed for hematoxylin and eosin staining. The histological changes were compared with an emphasis on changes in inflammation, epidermal/follicular wall thickness, and formation of cystic structures containing keratinized plugs (microcomedone-like cystic structures) in the dermis of groups A, B, and C.

\section{Immunohistochemistry}

Immunohistochemical staining was performed at week 2 after the first injection in group $A$ and after the second injection in groups $B$ and $C$ using standard techniques. The primary antibodies included: integrin $\alpha 6$ (used at 1:150 dilution; Santa Cruz Biotechnology, Inc., Santa Cruz, CA, USA), CD4 + T cells (1:300 dilution; Abcam, Cambridge, UK), CD8 + T cells (1:100 dilution; Abcam), neutrophil (1:80 dilution; Abcam), myeloperoxidase (MPO, 1:200 dilution; Abcam), interleukin (IL)-1 $\beta \quad(1: 150$ dilution; Abcam), matrix metalloproteinase (MMP)-2 (1:300 dilution; Abcam), MMP-3 (1:100 dilution; Abcam), MMP-9 (1:250 dilution; Abcam,), toll-like receptor (TLR)-2 (1:500 dilution; Abcam), and LL-37 (1:300 dilution; Abcam). The expression of inflammatory biomarkers per unit area in groups $A, B$, and $C$ was measured using Image $\mathrm{J}(\mathrm{NIH}$ Image, Bethesda, MD, USA).

\section{Western blot analysis}

Western blot analysis was performed at week 2 after the first injection in group $A$ and after the second injection in groups $B$ and $C$ to detect the anti-immunoglobulin $\mathrm{G}$ (IgG) antibody against $P$. acnes. $P$. acnes was lysed in a lysis buffer (25 mM Tris- $\mathrm{HCl}[\mathrm{pH} 7.2], 150 \mathrm{mM} \mathrm{KCl}, 0.1 \%$ sodium dodecyl sulfate, $1 \%$ Triton X-100, 5 mM EDTA [pH 8.0], and $2 \mathrm{mM}$ phenylmethylsulfonyl fluoride) supplemented with a protease inhibitor cocktail. Equal protein 
amounts were resolved by sodium dodecyl sulfate-polyacrylamide gel electrophoresis, transferred to a polyvinylidene difluoride membrane, and blotted with the mouse serum obtained from each group, followed by enhanced chemiluminescence and autoradiography.

\section{Statistical analysis}

The data were statistically analyzed using ANOVA. A $p$-value $<0.05$ was considered significant. All statistical analyses were performed using PASW software (Version 18.0; IBM Co., Armonk, NY, USA).

\section{RESULTS}

\section{Changes in inflammatory nodules in acne mouse model groups $A, B$, and $C$}

The size of the inflammatory nodules in all three groups decreased with time (Fig. 1A, B). There was a statistically significant difference in the size of the inflammatory nodules in groups B and C compared to group A at week 1, 2, 3 , and 4. Group $C$ showed a statistically significant decrease in inflammatory nodule size compared to group B at week 2 and 4 .

\section{Characteristics of histopathological findings in groups} $A, B$, and C

Epidermal thickness and the number and size of the microcomedone-like cysts were decreased in groups $B$ and $C$ compared to group A at week 4 (Fig. 2A $\sim D$ ). However, there were no statistically significant differences.

A

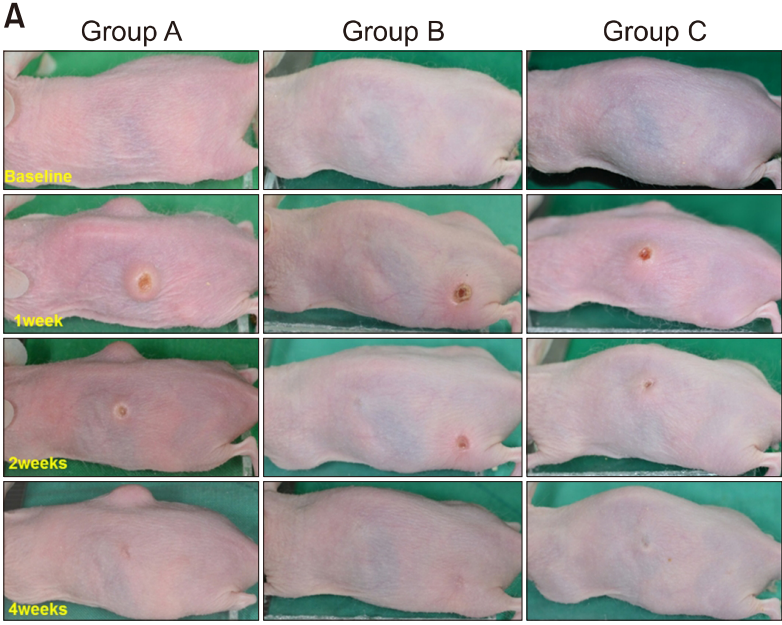

\section{Expression of inflammatory biomarkers in groups $A, B$, and $\mathrm{C}$}

The immunohistochemistry results showed that infiltration of CD8 T cells and neutrophils and the expression of IL- $1 \beta$, MMP-3 and MMP-9 in group $B$ and group $C$ were decreased when compared with group $A$ (Fig. 3A). On the contrary, infiltration of CD4 T cells and the expression of LL-37 in group $B$ and group $C$ were increased when compared with group A (Fig. 3A). However, there were no statistically significant differences in all three groups (Fig. 3A). Integrin $\alpha 6$ expression was increased in group $B$ and decreased in group $C$ when compared with group A (Fig. 3A, B). Integrin $\alpha 6$ expression showed a statistically significant decrease in group $B$ when compared with group $B$ $(p<0.05)$ (Fig. 3A).

\section{Western blot analysis using an anti-IgG antibody}

No immunoreactivity for an anti-lgG antibody against $P$. acnes was observed at week 2 after the first injection in the group A or at week 2 after the second injection in the group C. However, western blot analysis could detect an IgG antibody component against $P$. acnes (approximately $47 \mathrm{kDa}$ ) at week 2 after the second injection in the group B (Fig. 4).

\section{DISCUSSION}

Topical and systemic medications have been used for the treatment of acne ${ }^{8}$. However, bacterial resistance to antibiotics and adverse retinoid events have led to the devel-

B

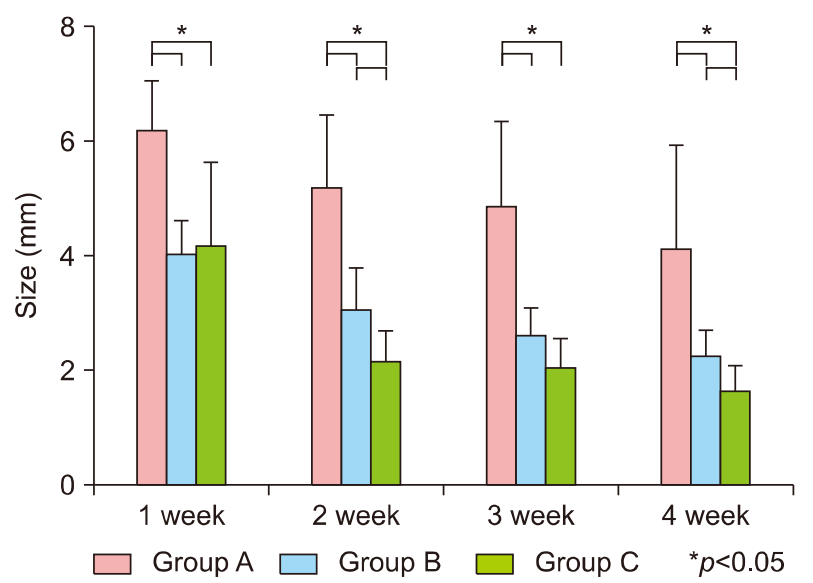

Fig. 1. (A) Changes in inflammatory nodule size in groups $A, B$, and $C$. The size of the inflammatory nodules in all groups decreased with time. (B) Changes in inflammatory nodule size in groups A, B, and C. The size of the inflammatory nodules in all groups decreased with time. The changes in size between groups $B / C$ and group $A$ were significantly different at weeks $1,2,3$, and 4 . The changes in size between group B and group C were significantly different at week 2 and 4. 
A

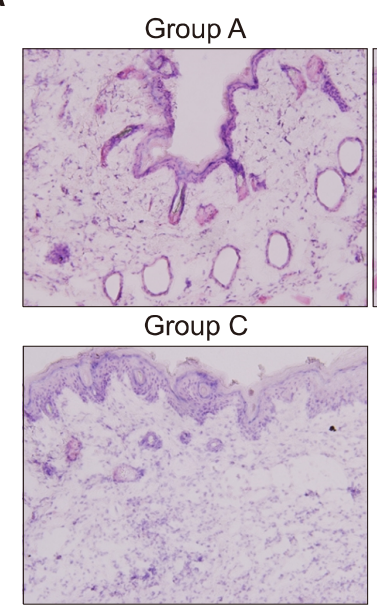

C

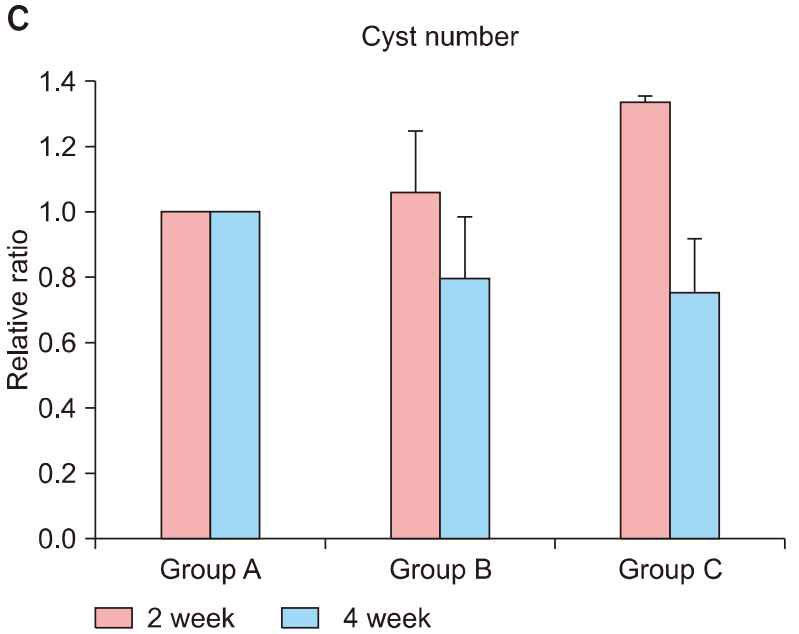

B

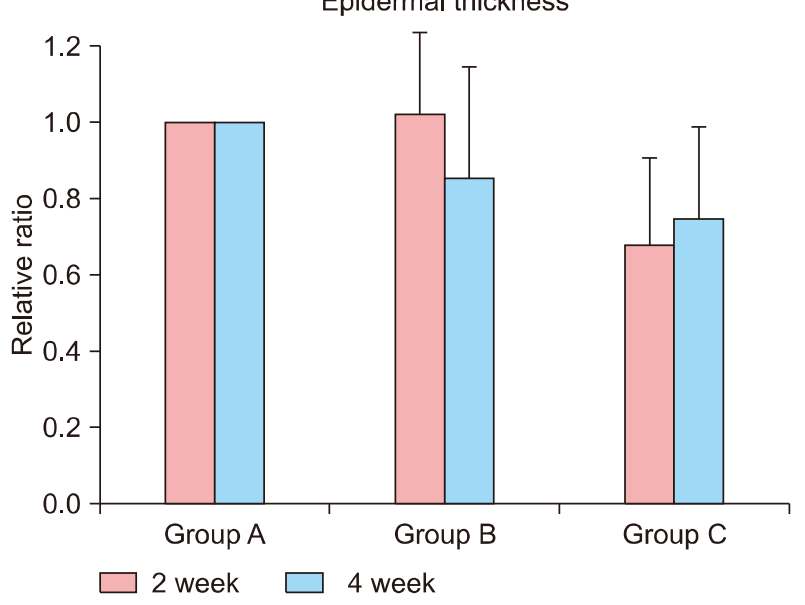

D

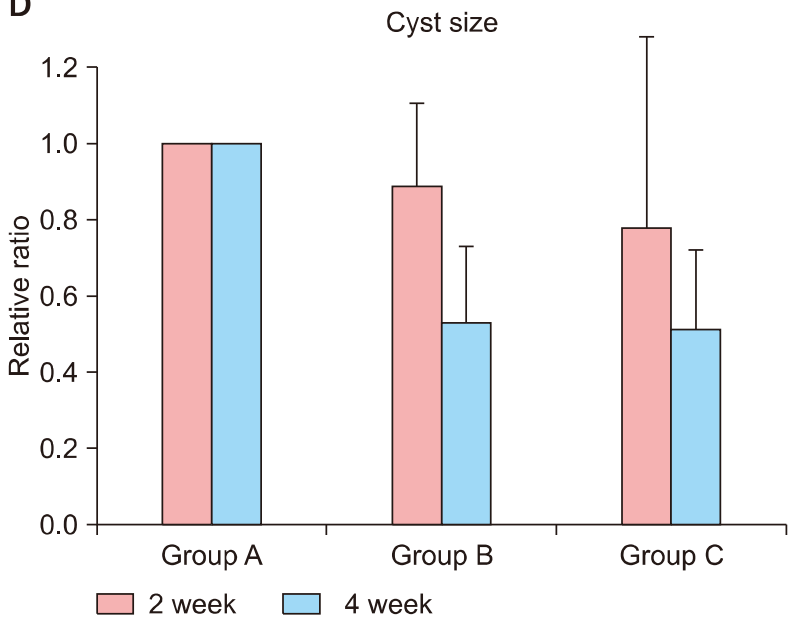

Fig. 2. (A) Histopathological findings of group $A$, group $B$ and group $C$ at week $4(H \& E, \times 200)$. (B) Changes in epidermal thickness. The epidermal thickness of the inflammatory nodules decreased with time, especially in group C, followed by group B and group A. However, there were no statistically significant differences. (C) Changes in the number of microcomedone-like cysts. The number of microcomedone-like cysts decreased with time, especially in group C, followed by group B and group A. However, there were no statistically significant differences. (D) Changes in the size of microcomedone-like cysts. The size of the microcomedone-like cysts decreased with time, especially in group C, followed by group B and group A. However, there were no statistically significant differences.

opment of new therapeutic modalities for acne ${ }^{9,10}$; vaccination has been introduced as one of the promising therapeutics for acne ${ }^{11}$.

Killed-pathogen-based vaccines have been used as a vaccine for the treatment of acne ${ }^{12}$ and an intranasal killed whole $P$. acnes preparation has been tested ${ }^{12}$. $P$. acnes has been established as a potent immunomodulator ${ }^{13}$, which can produce antibodies against secretary enzymes or cell wall molecules ${ }^{14}$. However, antibodies against $P$. acnes do not completely protect against the recurrence of acne, most likely because of insufficient production of protective antibodies against $P$. acnes. This study also showed the production of antibody in mice after treatment with $P$. acnes. Bacteriophages inhibited the production of the anti- body in mice after treatment with $P$. acnes.

Vaccination against cell wall-anchored sialidase has also been introduced ${ }^{15}$. Sialidase, a $P$. acnes virulence factor, is involved in degrading host tissue and inducing inflammation ${ }^{16}$. Nakatsuji et al. ${ }^{15}$ have reported that a sialidase-based acne vaccine showed good effects on $P$. acnes-induced ear inflammation. However, this vaccine may not be able to neutralize virulence factors secreted by $P$. acnes ${ }^{17}$. In addition, this vaccine may lack therapeutic effects for acne.

Monoclonal antibodies targeting Christie-Atkins-MunchPeterson (CAMP) factor have demonstrated improvement of acne ${ }^{17}$. P. acnes possesses a CAMP that acts as a potential secretory virulence factor to enhance hemolysis and 
A

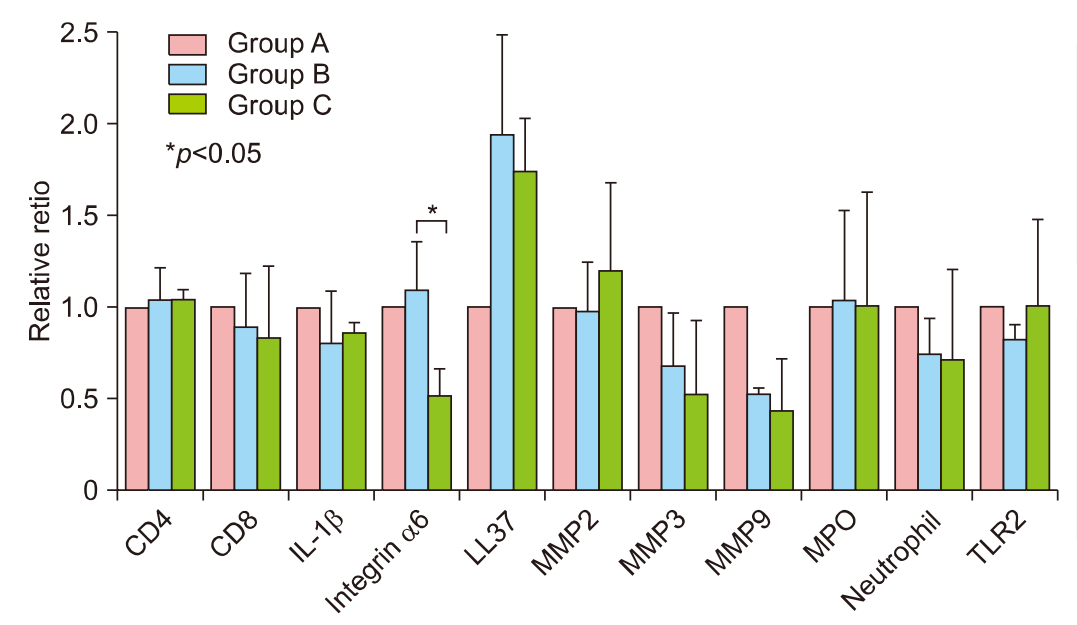

B

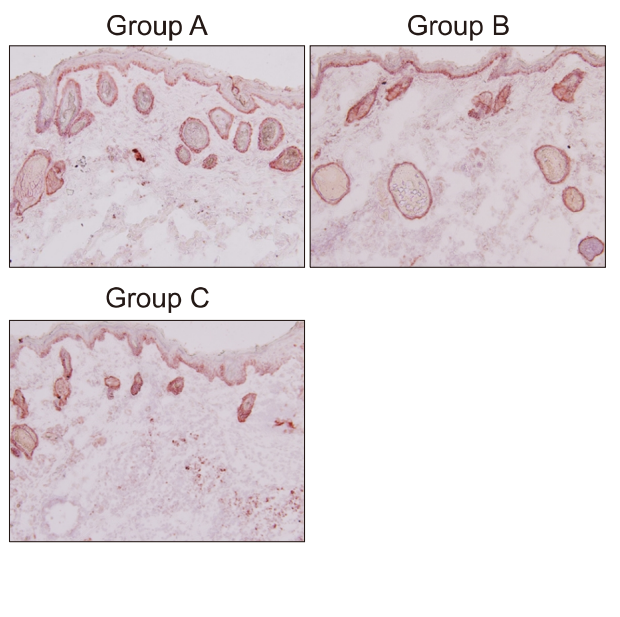

Fig. 3. (A) Immunohistochemistry analysis. Inflammatory biomarker expression was similar in all groups. There were no statistically significant differences except for integrin $\alpha 6$ between group B and group C. (B) Immunohistochemistry with integrin $\alpha 6$ in group A, group B and group C at week $2(\times 200)$. IL: interleukin, MMP: matrix metalloproteinase, MPO: myeloperoxidase, TLR: toll-like receptor.

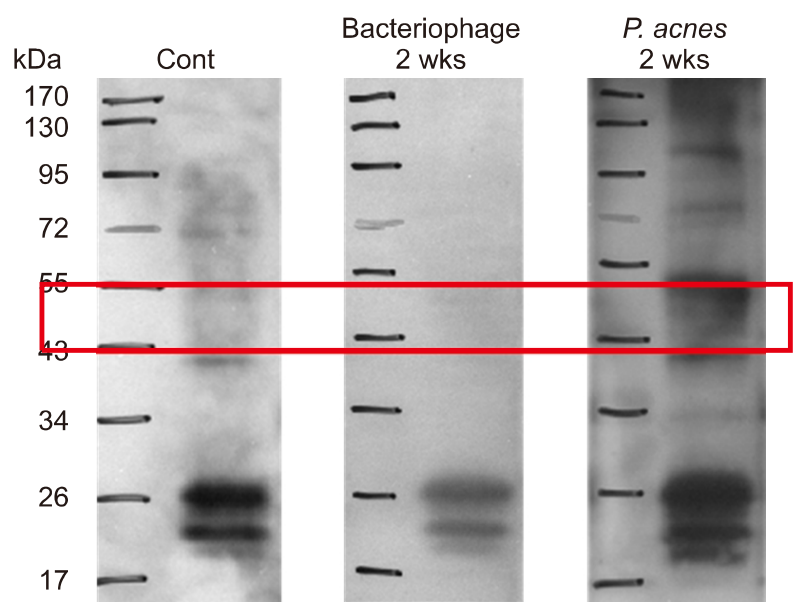

Fig. 4. Western blot analysis showed immunoreactivity to the immunoglobulin $\mathrm{G}$ antibody against Propionibacterium acnes $(P$. acnes) following treatment with $P$. acnes.

cytolysis $^{16,18}$. Nakatsuji et al. ${ }^{17}$ also investigated the treatment of acne using vaccines. They showed that passive immunization targeting secretory CAMP factors proteins can neutralize $P$. acnes virulence without disturbing other bacteria $^{17}$. Active immunization using a CAMP factor-targeted vaccine and passive neutralization of the CAMP factor showed roughly equal potency in terms of improving $P$. acnes-induced inflammation.

TLR vaccines and antimicrobial peptides (AMPs) constitute other optional vaccines for the treatment of acne. Recent studies have shown that TLRs and AMPs play an important role in the pathogenesis of inflammatory acne. Therefore, regulation of TLRs and AMPs could provide different therapeutic options for acne ${ }^{19}$.

Bacteriophages targeting $P$. acnes are also promising acne vaccine candidates ${ }^{20}$. Bacteriophages have several advantages over antibiotics against $P$. acnes. They are environmentally friendly, rapidly processed, less expensive, and well tolerated $^{5}$. In this study, we confirmed the potential of bacteriophages for the treatment of acne. The inflammatory nodules of HR-I mice decreased in size and microcomedone-like cysts was reduced in number and in size following bacteriophage treatment. In addition, epidermal thickness was decreased in bacteriophage treatment group. Epidermal hyperplasia can be induced by skin barrier disruption, calcium channel activation, metabotrophic receptor activation or unsaturated fatty acids ${ }^{21}$. Epidermal hyperplasia may be related to the induction of abnormal keratinization, which can be one of the causative factors of comedone formation. Furthermore, the decreased expression of integrin $\alpha 6$ after bacteriophage application shows its beneficial effect for the treatment of acne. Integrin $\alpha 6$ expression can be a response to inflammation and related to epidermal hyperplasia, leading to the abnormal differentiation ${ }^{2}$. Inflammatory biomarkers and cells, such as CD8 T cells, neutrophils, IL- $1 \beta$, MMP-3 and MMP-9, were also decreased after bacteriophage treatment. Antimicrobial peptides can play a protective role against $P$. acnes or induce inflammatory signal in acne vulgaris ${ }^{22}$. In this study, the increased expression of LL-37 by $P$. acnes was not inhibited by bacteriophages. Several parameters for bacteriophages need to be resolved 
for a comprehensive acne vaccine: delivery route, time point of delivery, dose, phage stability, infection rate, availability of highly efficient antibiotics, poor understanding of general aspects of phage life cycles, bacterial resistance to phage infection, and the possibility of temperate phages that integrate into the human genome ${ }^{23}$. Understanding the integration of temperate phages into the human genome is critical for the safety of phage therapy.

Recently, bacteriophages have been applied in a semi-solid preparation for the treatment of acne ${ }^{24}$. In addition, bacteriophages have also been formulated in a water-oil nanoemulsion $^{25}$. Bacteriophages against Acinetobacter baumannii have been applied in humans in the form of an antiseptic gel or a paraffin-oil-based product ${ }^{26}$. In light of these reports, a variety of formulations for the treatment of acne using bacteriophages that target $P$. acnes should be examined.

In conclusion, further investigation of bacteriophages targeting $P$. acnes should be conducted to gain a better understanding of bacteriophage characteristics and to develop more beneficial vaccines for the treatment of acne.

\section{ACKNOWLEDGMENT}

This research was supported by the Basic Science Research Program through the National Research Foundation of Korea (NRF) funded by the Ministry of Education, Science and Technology (2012R1A1A2007017).

\section{CONFLICTS OF INTEREST}

The authors have nothing to disclose.

\section{ORCID}

Min Ji Kim, https://orcid.org/0000-0001-6574-6485

Dong Hyuk Eun, https://orcid.org/0000-0003-4044-0679

Seok Min Kim, https://orcid.org/0000-0001-6470-7986

Jungmin Kim, https://orcid.org/0000-0002-1795-1844

Weon Ju Lee, https://orcid.org/0000-0001-5708-1305

\section{REFERENCES}

1. Shaheen B, Gonzalez M. Acne sans P. acnes. J Eur Acad Dermatol Venereol 2013;27:1-10.

2. Jeremy AH, Holland DB, Roberts SG, Thomson KF, Cunliffe WJ. Inflammatory events are involved in acne lesion initiation. J invest dermatol 2003;121:20-27.

3. Mirshahpanah P, Maibach HI. Models in acnegenesis. Cutan Ocul Toxicol 2007;26:195-202.
4. Jang YH, Lee KC, Lee SJ, Kim DW, Lee WJ. HR-1 mice: a new inflammatory acne mouse model. Ann Dermatol 2015; 27:257-264.

5. Jończyk-Matysiak E, Weber-Dąbrowska B, Żaczek $M$, Międzybrodzki R, Letkiewicz S, Łusiak-Szelchowska M, et al. Prospects of phage application in the treatment of acne caused by Propionibacterium acnes. Front Microbiol 2017; 8:164.

6. Jassim SA, Limoges RG. Natural solution to antibiotic resistance: bacteriophages 'The Living Drugs'. World J Microbiol Biotechnol 2014;30:2153-2170.

7. Marples RR. The microflora of the face and acne lesions. J Invest Dermatol 1974;62:326-331.

8. Sandoval LF, Hartel JK, Feldman SR. Current and future evidence-based acne treatment: a review. Expert Opin Pharmacother 2014;15:173-192.

9. Bienenfeld A, Nagler AR, Orlow SJ. Oral antibacterial therapy for acne vulgaris: an evidence-based review. Am J Clin Dermatol 2017;18:469-490.

10. Vallerand IA, Lewinson RT, Farris MS, Sibley $C D$, Ramien $\mathrm{ML}$, Bulloch AGM, et al. Efficacy and adverse events of oral isotretinoin for acne: a systematic review. $\mathrm{Br} J$ Dermatol 2018;178:76-85.

11. Nakatsuji $T$, Rasochova $L$, Huang $C M$. Vaccine therapy for P. acnes-associated diseases. Infect Disord Drug Targets 2008;8:160-165.

12. Nakatsuji T, Liu YT, Huang CP, Zoubouis CC, Gallo RL, Huang CM. Antibodies elicited by inactivated Propionibacterium acnes-based vaccines exert protective immunity and attenuate the IL-8 production in human sebocytes: relevance to therapy for acne vulgaris. J Invest Dermatol 2008;128: 2451-2457.

13. Mussalem JS, Vasconcelos JR, Squaiella CC, Ananias RZ, Braga EG, Rodrigues MM, et al. Adjuvant effect of the Propionibacterium acnes and its purified soluble polysaccharide on the immunization with plasmidial DNA containing a Trypanosoma cruzi gene. Microbiol Immunol 2006;50:253-263.

14. Lodes MJ, Secrist $H$, Benson DR, Jen $S$, Shanebeck KD, Guderian J, et al. Variable expression of immunoreactive surface proteins of Propionibacterium acnes. Microbiology 2006;152:3667-3681.

15. Nakatsuji T, Liu YT, Huang CP, Zouboulis CC, Gallo RL, Huang CM. Vaccination targeting a surface sialidase of $P$. acnes: implication for new treatment of acne vulgaris. PLoS One 2008;3:e1551.

16. Brüggemann $H$. Insights in the pathogenic potential of Propionibacterium acnes from its complete genome. Semin Cutan Med Surg 2005;24:67-72.

17. Nakatsuji T, Tang DC, Zhang L, Gallo RL, Huang CM. Propionibacterium acnes CAMP factor and host acid sphingomyelinase contribute to bacterial virulence: potential targets for inflammatory acne treatment. PLoS One 2011;6: e14797.

18. Lo CW, Lai YK, Liu YT, Gallo RL, Huang CM. Staphylococcus aureus hijacks a skin commensal to intensify its virulence: immunization targeting beta-hemolysin and CAMP factor. J 
Invest Dermatol 2011;131:401-409.

19. Ozlu E, Karadag AS, Ozkanli S, Oguztuzun S, Kilic M, Zemheri E, et al. Comparison of TLR-2, TLR-4, and antimicrobial peptide levels in different lesions of acne vulgaris. Cutan Ocul Toxicol 2016;35:300-309.

20. Górski A, Dąbrowska K, Hodyra-Stefaniak K, Borysowski J, Międzybrodzki R, Weber-Dąbrowska B. Phages targeting infected tissues: novel approach to phage therapy. Future Microbiol 2015;10:199-204.

21. Katsuta $Y$, lida $T$, Inomata $S$, Denda $M$. Unsaturated fatty acids induce calcium influx into keratinocytes and cause abnormal differentiation of epidermis. J Invest Dermatol 2005;124:1008-1013.

22. Borovaya A, Dombrowski Y, Zwicker S, Olisova O, Ruzicka $\mathrm{T}$, Wolf $\mathrm{R}$, et al. Isotretinoin therapy changes the expression of antimicrobial peptides in acne vulgaris. Arch Dermatol
Res 2014;306:689-700.

23. Brüggemann $H$, Lood R. Bacteriophages infecting propionibacterium acnes. Biomed Res Int 2013;2013:705741.

24. Brown TL, Petrovski S, Dyson ZA, Seviour R, Tucci J. The formulation of bacteriophage in a semi solid preparation for control of Propionibacterium acnes growth. PLoS One 2016;10:e0151184.

25. Esteban PP, Alves DR, Enright MC, Bean JE, Gaudion A, Jenkins AT, et al. Enhancement of the antimicrobial properties of bacteriophage-K via stabilization using oil-in-water nano-emulsions. Biotechnol Prog 2014;30:932944.

26. Chen LK, Liu LY, Hu A, Chang KC, Lin NT, Lai MJ, et al. Potential of bacteriophage $\Phi A B 2$ as an environmental biocontrol agent for the control of multidrug-resistant Acinetobacter baumannii. BMC Microbiol 2013;13:154. 